\title{
259 可撓性積層はりの大たわみ変形解析 \\ Theoretical Analysis of Large Deformations in a Flexible Multi-Layered Beam
}

正大槻 敦巳（名城大理工） ○学 林 克典 (名城大理工 院)

Atsumi OHTSUKI, Meijo University, 1-chome 501-banchi, Shiogamaguchi, Tempaku-ku, Nagoya, 468-8502 Japan

Katsunori HAYASHI, Graduate student of Meijo University

Key Words: $\quad$ Elasticity, Large Deflection, Non-linear Problem, Elastica Problem, Multi-Layered Beam

\section{1. 緒言}

金属系材料あるいは高分子材料の薄板や細線など極め て大きくたわみやすい材料がばね用部材や機械の構造用 部材として広く用いられている.しかも，最近ではこれ らは単体之してだけではなく，部材としての機能何上の ため積層化して使用されることも多くなっている．可撓 性単層はりの大変形については, 幾つかの解析例がある が(1) (3)，積層はりについては不明な点が多い。そこで, 本論文では可撓性の大きい積層薄板の大変形特性につい て, 両端回転自由な真直はりが軸方向圧縮荷重を受けた 場合を例にとり非線形解析したもので，だ円積分を用い た解析解を与えるとともに、解析理論の有効性を実験で 確かめた．ところで，積層はりは均質等方体を組合わせ たはりで, 負荷の際は相互に滑ることなく一つのはりと して変形し, Euler-Bernoulli の仮定が成り立つものと考え る.また, 理論の適応範囲は弾性領域とし, はりは不伸 長で, せん断力の影響, ポアッソン効果などは考慮しな いこととした。

\section{2. 基硴理詥}

図 1 に示すように, 全長 $2 L$ の両端回転自由な積層はり は, 両端部に軸方向圧縮荷重 $P$ を受ける。はりにおける 変形の対称性を考虑して解析は右半分について行う。座 標原点を $\mathrm{A}$ とし，原点から鈶直下向きに距離 $y$ をとり， 水平方向に距離 $x$ をとる. 水平方向変位を入, 垂直方向変 位を $\delta$, 先端たわみ角を $\theta_{\mathrm{B}}$, たわみ曲線の円弧長さを $s$, 曲率半径を $R$, 積層はりを構成する各部材要素のヤング率 を $E_{1} \sim E_{n}$, 中立軸に関する各部材要素の断面二次モ一メ ントを $I_{1} \sim I_{n}$ とする. 特に, 図 2 は 2 層薄板 $(n=2)$ を示した もので, $z$ 軸から中立軸までの距離を $\bar{y}$ ，中立軸から任意 軸までの距離を $y$,さらに $z$ 軸から任意軸までの距離を $y_{\mathrm{Z}}$ とする。曲げ変形において, 中立軸から各部材要素まで の距離を $y_{1} \sim y_{n}$ とすると, 中立軸に対する曲率の関係から

$\frac{1}{R}=\frac{\sigma_{1}}{E_{1} y_{1}}=\frac{\sigma_{2}}{E_{2} y_{2}}=\cdots \cdot=\frac{\sigma_{i}}{E_{i} y_{i}}=\cdot \cdots=\frac{\sigma_{n}}{E_{n} y_{n}}$

また，断面に作用する曲げモーメント $M$ は， $A_{i}$ を各部 材要素の断面積とすれば, 式(1)より

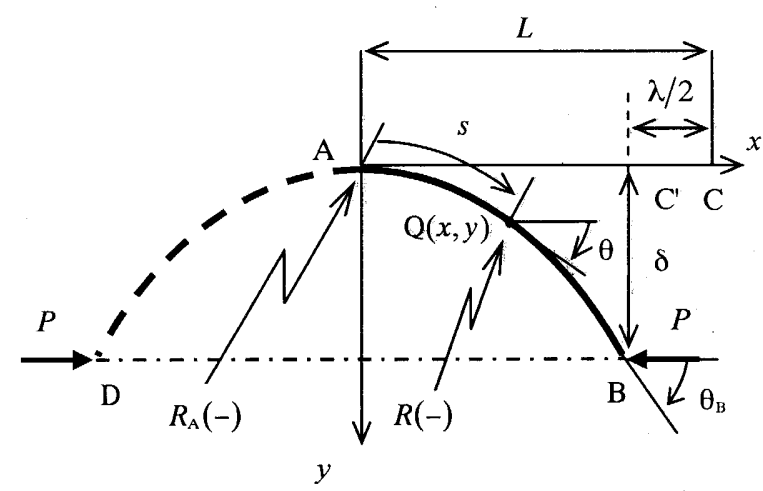

Fig.1 Schematic configuration of multi-layered beam subjected to axial compressive forces at both hinged supports.

$$
M=\sum_{i=1}^{n}\left(\frac{E_{i}}{R} \int_{A_{i}} y_{i}^{2} d A\right)=\frac{1}{R} \sum_{i=1}^{n}\left(E_{i} I_{i}\right)
$$

したがって，たわみの関係式として次式(3),(4)が成り立つ.

$$
\frac{1}{R}=-\frac{d \theta}{d s}=\frac{M}{\sum_{i}^{n}\left(E_{i} I_{i}\right)}
$$

$d x=d s \cdot \cos \theta, \quad d y=d s \cdot \sin \theta$

はりの任意点 $\mathrm{Q}(x, y)$ に作用する曲げモーメントは

$M=P \cdot y+M_{\mathrm{A}}$

ここで, 次の無次元量

$$
\left.\begin{array}{l}
\xi=\frac{x}{L}, \eta=\frac{y}{L}, \zeta=\frac{s}{L}, \rho=\frac{R}{L} \\
\gamma=\frac{P L^{2}}{\sum_{i=1}^{n}\left(E_{i} I_{i}\right)}, \alpha=\frac{M_{\mathrm{A}} L}{\sum_{i=1}^{n}\left(E_{i} I_{i}\right)}
\end{array}\right\}
$$

を導入すれば，最終的に，たわみの基礎式は式(3)〜(5)より

$$
\frac{d \theta}{d \zeta}= \pm \sqrt{2 \gamma\left(\cos \theta-\cos \theta_{\mathrm{B}}\right)}
$$

なお, 式(7)右辺の正負符号 $( \pm)$ は無次元円弧長さとに対する 日の増滅特性によって選択されるもので, 本解析における変 形状態では常に正符号(+)を採用する。

さらに, 上式(7)において, 新しく角度变数 $\phi$, 変数 $k$

$$
\left.\begin{array}{l}
\cos \theta_{\mathrm{B}}=1-2 k^{2} \\
\cos \theta=1-2 k^{2} \cdot \sin ^{2} \phi \quad\left(0 \leqq \phi \leqq \frac{\pi}{2}\right)
\end{array}\right\}
$$

とおき, $\theta$ について新角度変数 $\phi に$ 変換し, 整理すると

$$
\begin{aligned}
& d \zeta=\frac{d \phi}{\sqrt{\gamma\left(1-k^{2} \cdot \sin ^{2} \phi\right)}} \cdots \ldots \ldots \ldots \ldots \ldots \ldots \ldots \ldots \\
& d \eta=\frac{2 k \cdot \sin \phi}{\sqrt{\gamma}} d \phi \text {. } \\
& d \xi=\left\{\frac{2}{\sqrt{\gamma}} \sqrt{1-k^{2} \cdot \sin ^{2} \phi}-\frac{1}{\sqrt{\gamma} \sqrt{1-k^{2} \cdot \sin ^{2} \phi}}\right\} d \phi
\end{aligned}
$$

これら微少量の式を角度変数 $\phi_{\mathrm{A}} \sim \phi_{\mathrm{C}}\left[\right.$ 実角度 $\theta_{\mathrm{A}} \sim \theta_{\mathrm{C}}$ に対応 $]$ にわたって積分すれば, 任意点 $\mathrm{Q}(x, y)$ までの無次元円弧長 さそ, 無次元水平距離 $\xi$, 無次元たわみ

先端 $\mathrm{B}$ に関しては, 最終的に次式が得られる。

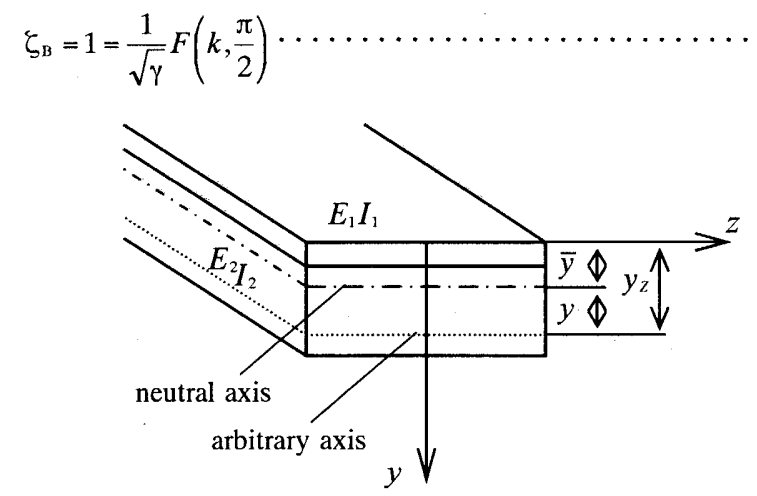




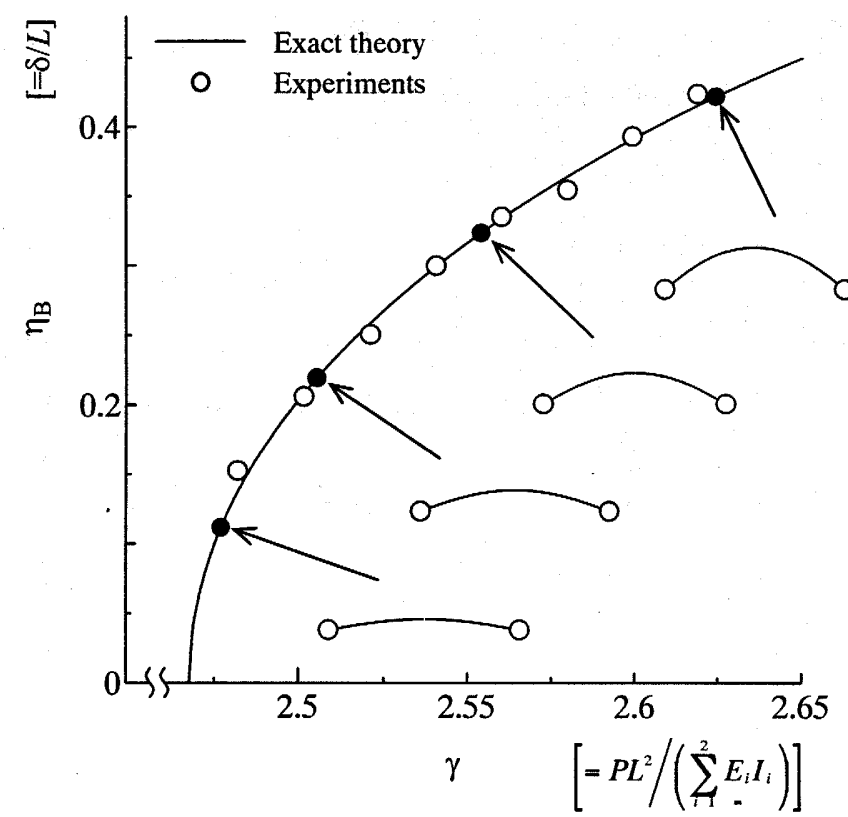

Fig.3 Relationship between non-dimensional deflection $\eta_{\mathrm{B}}$ and non-dimensional load $\gamma(n=2)$.

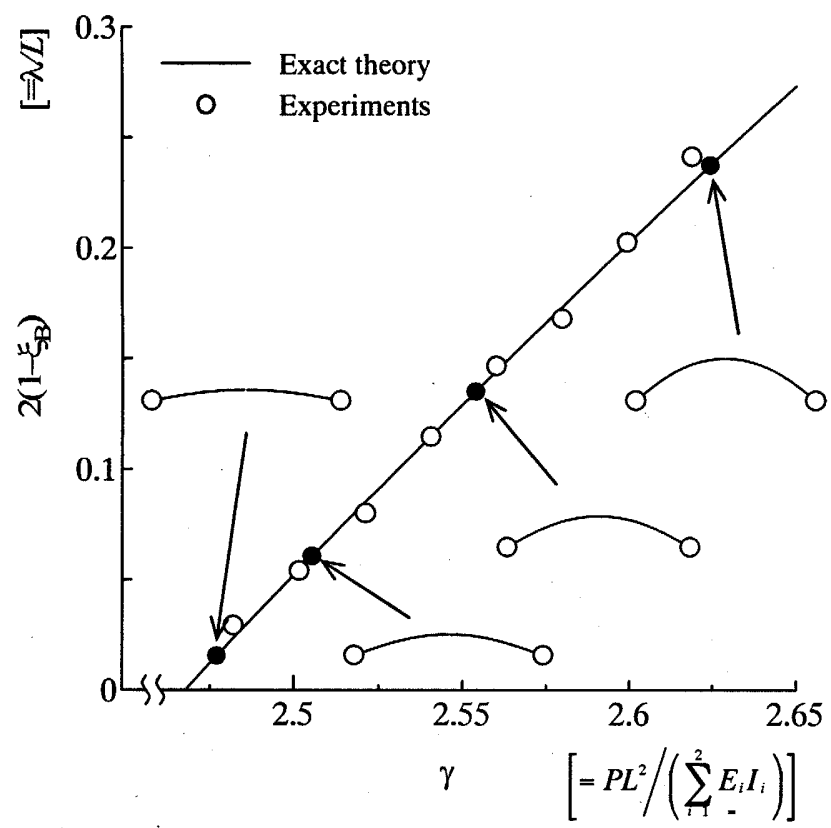

Fig.4 Relationship between non-dimensional elongation $\xi_{B}$ and non-dimensional load $\gamma(n=2)$.

$$
\begin{aligned}
& \eta_{\mathrm{B}}=\frac{\delta}{L}=\frac{2 k}{\sqrt{\gamma}}\left(1-\cos \frac{\pi}{2}\right)=\frac{2 k}{\sqrt{\gamma}} \cdots \cdots \cdots \\
& \xi_{\mathrm{B}}=\frac{L-\lambda / 2}{L}=\frac{1}{\sqrt{\gamma}}\left\{2 E\left(k, \frac{\pi}{2}\right)-F\left(k, \frac{\pi}{2}\right)\right\}
\end{aligned}
$$

なお, 関数 $F(k, \phi), E(k, \phi)$ はそれぞれ Legendre-Jacobi のだ 円積分第一種および第二種を表す。

ところで, 積層はりが薄板の場合には, 任意部材要素 の中立軸に関する断面二次モーメント $I_{i}$ の一般式は

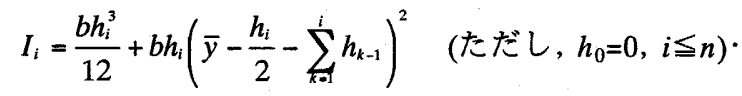

で表され, 中立軸の位置 $\bar{y}$ は, $i$ 番目の部材の横断面が $z$ 軸に関して持つ断面一次モーメントを $\left(S_{i}\right)_{z}$ とすれば

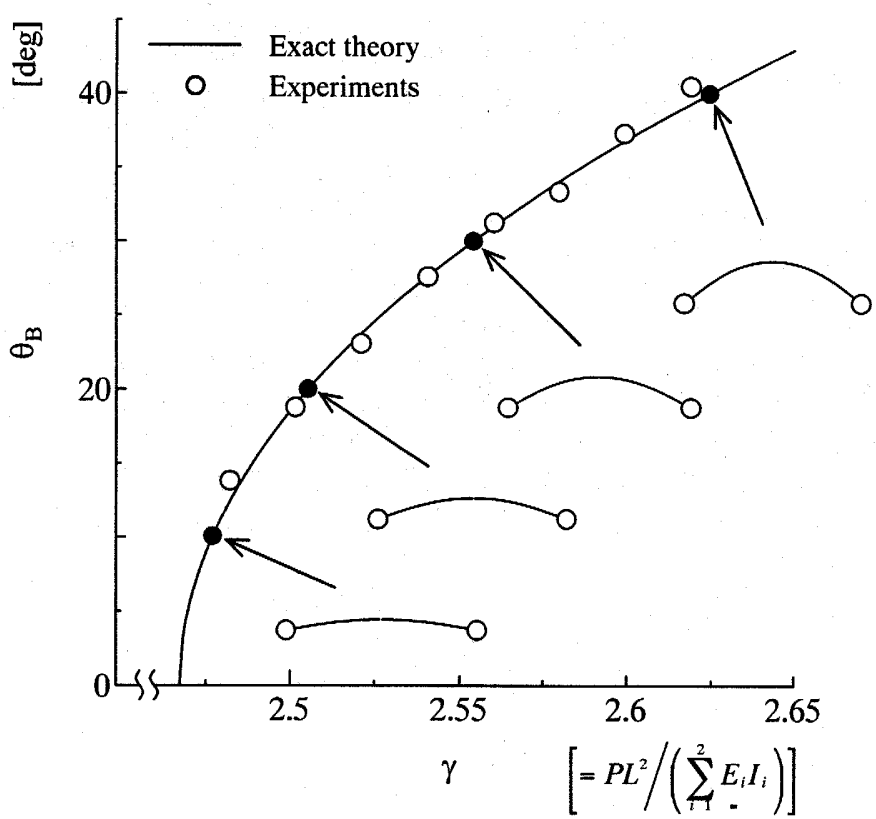

Fig.5 Relationship between deflection angle $\theta_{\mathrm{B}}$ and non-dimensional load $\gamma(n=2)$.

$$
\bar{y}=\frac{\sum_{i=1}^{n} E_{i}\left(S_{i}\right)_{2}}{\sum_{i=1}^{n}\left(E_{i} A_{i}\right)}
$$

となる.ここで $\left(S_{i}\right)_{z}$ の一般式は

$$
\left(S_{i}\right)_{2}=\frac{b h_{i}^{2}}{2}+b h_{i}\left(\sum_{k-1}^{i} h_{k-1}\right)
$$

\section{3. 理詥解析及び测定例}

ステンレス鋼(SUS)の薄板（第 1 層, 幅 $b_{1}: 27.0 \mathrm{~mm}$, 長 さ $2 L_{1}: 300 \mathrm{~mm}$, 厚さ $h_{1}: 0.100 \mathrm{~mm}$, ヤング率 $E_{1}: 205.6 \mathrm{GPa}$ ） と高分子材料(PVC)の薄板(第 2 層, 幅 $b_{2}: 27.0 \mathrm{~mm}$, 長さ $2 L_{2}: 300 \mathrm{~mm}$, 厚さ $h_{2}: 0.515 \mathrm{~mm}$, ヤング率 $\left.E_{2}: 3.41 \mathrm{GPa}\right)$ から構成される 2 層薄板の軸圧縮はりにおける大たわみ変 形の解析結果をそれぞれ図 3 （無次元荷重： $\gamma$ と無次元たわ み: $\eta_{\mathrm{B}}$ の関係），図 4（無次元荷重: $\gamma$ と無次元先端水平移 動距離 : 1- $\xi_{\mathrm{B}}$ の関係), 図 5 (無次元荷重 $\gamma$ と荷重端のたわ み角度 $\theta_{\mathrm{B}}$ の関係）に示す。いずれの図においても，併記し た実験結果と解析理論はかなり良い一致性を示した。

\section{4. むすび}

本研究の解析の結果, 次の諸点が明らかとなった.

(1) 従来未知であった両端回転自由の軸圧縮積層はり（解 析例は 2 層薄板）の大たわみ変形挙動が予想できる.

（2）垂直たわみや水平方向変位は軸圧縮荷重によって曲線 的に変化する.

(3) 無次元荷重は見かけの断面は同じでも，構成する層の 断面二次モーメント, ヤング率によって変化する.

(4) 大たわみ実験による無次元水平距離, 無次元たわみな どの実験結果は解析理論とかなり良い一致を示し, 導出の 大たわみ理論の有効性が確認された。

\section{考文部}

(1) Barten.H.J., Quart.Appl.Math., 2 (1945), 168-171.

(2) Bisshop.K.E. \& Drucker.D.C., Quart.Appl.Math., 3 (1945), 272-275.

(3)大槻, 名城大学理工学部研究報告, 26 (1986), 21-28. 